\title{
Memória da Assembleia Constituinte de 1987/1980: o Sistema Financeiro
}

\author{
JOSÉ ROBERTO R. AFONSO
}

Economista, Doutor pela Unicamp, Mestre pela UFRJ, Especialista em Finanças Públicas, Consultor Técnico Especial do Senado Federal. Foi colaborador da Comissão de Finanças na Assembleia Constituinte de 1987/88.

RESUMO: As deliberações da Assembleia Nacional Constituinte de 1987/88 sobre o Sistema Financeiro Nacional foram marcadas por inovações e polêmicas. A começar pela opção inédita de se dedicar um capítulo específico da Constituição ao tema. Desde os trabalhos iniciais proliferaram propostas tidas como populistas - desde a nacionalização e estatização do sistema bancário, que não chegaram a ser aprovadas, até a fixação da taxa de juros, consequente crime de usura e anistia para dívidas dos produtores rurais junto aos bancos oficiais. Como paliativo, a eficácia de todas as normas foram remetidas para posterior lei complementar. Até que, em 2003, emenda constitucional suprimiu todos incisos e parágrafos do art. 192 e manteve a remissão, agora no plural, para que as leis complementares regulamente 0 assunto.

PALAVRAS-CHAVE: Constituição; Congresso Nacional; Sistema Financeiro Nacional.

ABSTRACT: The deliberations of the Constituent Assembly of 1987/88 on the national financial system were marked by innovation and controversy. Starting with the unique option to devote a chapter to the subject of the Constitution. Since the initial proposals proliferated seen as populist - from the nationalization and nationalization of the banking system, which did not come to be approved until the setting of interest rates and the resulting crime of usury to amnesty for debts of farmers from the banks official. As a stopgap, the effectiveness of all standards were referred for further supplementary law. Until 2003 constitutional amendment removed all sections and paragraphs of article 192 and maintained remission, now in the plural, so that additional laws regulating the matter.

KEYWORDS: Constitution; Congress; National Financial System.

SUMÁRIO: Introdução; 1 Subcomissão do Sistema Financeiro; 2 Comissão de finanças; 3 Comissão de sistematização; 4 Plenário; 5 Observações finais; Referências.

\section{INTRODUÇÃO}

A Constituição da República, promulgada em outubro de 1988, inovou ao incluir um capítulo especialmente dedicado ao Sistema Financeiro (constituído por seu art. 192), entre aqueles contemplados pelo título "Da Ordem Econômica".

Nunca uma Constituição brasileira tinha dedicado uma divisão do texto especialmente à matéria - em fato, nunca sequer tinha sido adotado alguma 
disposição no corpo permanente constitucional dedicado a regular tal sistema, o banco central ou as instituições financeiras. As Constituições brasileiras anteriores limitavam-se a remeter para a legislação infraconstitucional as definições sobre sistema monetário, títulos, metais, políticas de crédito e de câmbio e direito financeiro, isto em meio às competências da União. Essa tradição brasileira era compatível com o tratamento dispensado pela maioria das Constituições estrangeiras que não dedicam normas quanto menos sessões específicas para o Sistema Financeiro. Aliás, mesmo os raros casos - como das Constituições da Suíça de 1874 e do Peru de 1979 -, a atenção se volta para o papel do banco central e princípios básicos do sistema.

Esta foi uma das matérias que mais despertou discussões e polêmicas, quase sempre inflamadas e com inegável componente ideológico, durante os trabalhos da Assembleia Nacional Constituinte de 1987/88. De certa forma, os debates seguiram depois de promulgada a Carta Magna porque geraram importantes questionamentos na Justiça. O caso mais emblemático foi o da restauração do chamado crime de usura vinculado à tentativa de fixar um limite para a taxa de juro real praticada no crédito bancário no País, que não deveria ultrapassar o nível de $12 \%$, taxa muito inferior à praticada na época. Previsto em um parágrafo do artigo da Constituição que delegava à lei complementar a regulação do Sistema Financeiro, o Supremo Tribunal Federal (STF) interpretou que tal teto só precisaria ser respeitado depois que fosse editada a citada lei geral' . Não custa reproduzir a redação original dada pela Constituição promulgada em outubro de 1988 ao capítulo em questão:

\section{CAPÍTULO IV \\ DO SISTEMA FINANCEIRO NACIONAL}

Art. 192. O Sistema Financeiro Nacional, estruturado de forma a promover o desenvolvimento equilibrado do País e a servir aos interesses da coletividade, será regulado em lei complementar, que disporá, inclusive, sobre:

I - a autorização para o funcionamento das instituições financeiras, assegurado às instituições bancárias oficiais e privadas acesso a todos os instrumentos do mercado financeiro bancário, sendo vedada a essas instituições a participação em atividades não previstas na autorização de que trata este inciso;

II - autorização e funcionamento dos estabelecimentos de seguro, previdência e capitalização, bem como do órgão oficial fiscalizador e do órgão oficial ressegurador;

II - autorização e funcionamento dos estabelecimentos de seguro, resseguro, previdência e capitalização, bem como do órgão oficial fiscalizador;

III - as condições para a participação do capital estrangeiro nas instituições a que se referem os incisos anteriores, tendo em vista, especialmente:

1 Para uma breve descrição do tratamento dispensado pelo STF ao sistema financeiro, ver o seguinte link do portal da Corte: http://bit.ly/16IL1iK. 
a) os interesses nacionais;

b) os acordos internacionais.

IV - a organização, o funcionamento e as atribuições do banco central e demais instituições financeiras públicas e privadas;

$\mathrm{V}$ - os requisitos para a designação de membros da diretoria do banco central e demais instituições financeiras, bem como seus impedimentos após o exercício do cargo;

$\mathrm{VI}$ - a criação de fundo ou seguro, com o objetivo de proteger a economia popular, garantindo créditos, aplicações e depósitos até determinado valor, vedada a participação de recursos da União;

VII - os critérios restritivos da transferência de poupança de regiões com renda inferior à média nacional para outras de maior desenvolvimento;

VIII - o funcionamento das cooperativas de crédito e os requisitos para que possam ter condições de operacionalidade e estruturação próprias das instituições financeiras.

$\S 1^{\circ} \mathrm{A}$ autorização a que se referem os incisos I e II será inegociável e intransferível, permitida a transmissão do controle da pessoa jurídica titular, e concedida sem ônus, na forma da lei do Sistema Financeiro Nacional, a pessoa jurídica cujos diretores tenham capacidade técnica e reputação ilibada, e que comprove capacidade econômica compatível com o empreendimento.

$\S 2^{\mathrm{o}}$ Os recursos financeiros relativos a programas e projetos de caráter regional, de responsabilidade da União, serão depositados em suas instituições regionais de crédito e por elas aplicados.

$\S 3^{\circ}$ As taxas de juros reais, nelas incluídas comissões e quaisquer outras remunerações direta ou indiretamente referidas à concessão de crédito, não poderão ser superiores a doze por cento ao ano; a cobrança acima deste limite será conceituada como crime de usura, punido, em todas as suas modalidades, nos termos que a lei determinar.

Poucos anos depois, o Congresso Nacional aprovou uma Emenda Constitucional, no $\mathrm{n}^{\mathbf{0}}$, de 29.05.2003, que suprimiu essas e outras matérias de serem reguladas e por uma única lei complementar. Na prática, essa decisão de "desconstitucionalizar" a matéria constituiu mais um e derradeiro lance das disputas, inclusive ideológicas, travadas durante a Constituinte. O art. 192 passou a apresentar a seguinte redação, limitada ao caput, depois de suprimidos todos os incisos e parágrafos.

Art. 192. O Sistema Financeiro Nacional, estruturado de forma a promover o desenvolvimento equilibrado do País e a servir aos interesses da coletividade, em todas as partes que o compõem, abrangendo as cooperativas de crédito, será regulado por leis complementares que disporão, inclusive, sobre a participação do capital estrangeiro nas instituições que o integram.

Neste contexto, julgamos oportuno resgatar a memória dos trabalhos daquela Assembleia de 1987/88 em torno da matéria do Sistema Financeiro, obje- 
tivo deste artigo. Ele está estruturado em seções que refletem as diferentes fases do processo de elaboração da Constituição vigente. Chama-se a atenção que os relatórios, as emendas e os anais dos debates e das votações consultados para elaboração deste artigo agora estão disponíveis em meio eletrônico, por iniciativas do Congresso Nacional - em particular, é recomendado o portal chamado "Constituição cidadã", hospedado no sítio na Internet da Câmara dos Deputados $^{2}$, sem contar a gravação de todo o acervo em CD lançado por ocasião dos 20 anos da promulgação ${ }^{3}$.

Em todas as fases do processo constituinte, entre março de 1987 e outubro de 1988, foi seguida uma rotina: partia-se do anteprojeto aprovado na etapa anterior e/ou de substitutivo elaborado pelo Relator. Esse documento tido como base recebia emendas, que eram submetidas ao crivo do Relator, e que apresentava o seu substitutivo. Este e as emendas eram apreciadas e votadas, resultando no anteprojeto daquela fase de trabalho.

Embora o Sistema Financeiro viesse a compor o título da ordem econômica, ele foi debatido na primeira fase do processo constituinte junto com o sistema tributário e os orçamentos, que vieram a compor outro e anterior título da Constituição de 1988. Segundo depoimento do Relator da comissão que tratou dessas matérias, o constituinte José Serra ${ }^{4}$, isso decorreu de uma questão de certa forma numérica: quando instalada a Assembleia e decidida começar os trabalhos por comissões temáticas, ficou estabelecido que cada uma delas seria compostas por três subcomissões. Faltando um terceiro tema para a comissão que trataria de tributação e orçamentação, teria sido decidido que seria o Sistema Financeiro 5 .

\section{SUBCOMISSÃO DO SISTEMA FINANCEIRO}

$\mathrm{Na}$ fase inicial da Assembleia Constituinte, as normas relativas ao Sistema Financeiro Nacional foram objeto de estudo específico da Subcomissão do Sistema Financeiro $(\mathrm{V}-\mathrm{c})$, uma das três subcomissões que integravam a Comissão do Sistema Tributário, Orçamento e Finanças (V). A subcomissão foi presidida pelo constituinte Cid Sabóia de Carvalho e teve como Relator o constituinte Fernando Gasparian.

Nesta fase de trabalho participaram diretamente técnicos, economistas e autoridades governamentais ligadas ao tema, que expunham e debatiam análi-

2 A página no sítio da Câmara está disponível no seguinte link: <http://www2.camara.leg.br/atividadelegislativa/legislacao/Constituicoes_Brasileiras/constituicao-cidada $>$.

3 Ver notícia: http://bit.ly/16IIDZj.

4 Ver palestra de José Serra em seminário realizado pelo Instituto de Direito Público - IDP, de Brasília, em 05.04.2013, cujo vídeo está disponível em: http://bit.ly/16IKDRr.

5 Tratativas políticas à parte, recomenda-se a análise de Patury (1992), que bem demarca a fronteira que lei complementares futuras deveriam obedecer entre finanças públicas e privadas - esta última, tratada no art. 195 e alguns incisos do art.193 da Carta Magna. 
ses e sugestões com os parlamentares. A participação direta de não parlamentares só ocorreu nesta etapa e na da comissão temática, sendo que, neste caso, as palestras eram organizadas em comum entre Subcomissão e Comissão de Finanças. Em seguida, tomando por base também sugestões encaminhadas pelos parlamentares, o Relator da subcomissão apresentou uma primeira versão de anteprojeto, acompanhada de um diagnóstico de Sistema Financeiro.

Questão básica a se verificar, nesta fase introdutória dos trabalhos, respeita aos motivos que levaram a Assembleia Constituinte a dedicar tanta atenção ao Sistema Financeiro (a ponto de merecer estudos de uma subcomissão específica), já que essa matéria nunca foi objeto de maior enfoque na tradição constitucional brasileira e mesmo nas Constituições de muitos países estrangeiros $^{6}$. O diagnóstico do constituinte Fernando Gasparian foi o seguinte:

A maximização do processo de desenvolvimento, por sua vez, pressupõe a existência de sistema financeiro eficiente, capaz de, ao menor custo, reunir as poupanças diversas na economia e direcioná-las para o financiamento de investimentos que proporcionem retorno compatível com os objetivos globais da sociedade. A exemplo do que ocorre em grande número de países, a Constituição deve contemplar preceitos compatíveis com a importância desse segmento da atividade econômica... decorridos mais de 22 anos desde o início da montagem do atual Sistema Financeiro Nacional, a economia e a sociedade brasileira vivenciaram sensíveis transformações estruturais. Inexistindo na Constituição vigente dispositivos balizadores da intermediação financeira, seria de certo modo natural que problemas de toda ordem fossem acumulando-se [...].

A ausência de princípios constitucionais na Carta em vigor não apenas deixou de nortear os intermediários financeiros para as suas funções sociais como acabou por ensejar práticas ora ilegítimas, ora ilegais e, principalmente, a usurpação da competência legislativa que deveria caber ao Congresso.

Assim, tendo em vista uma série de distorções do Sistema Financeiro - como o poder arbitrário das autoridades econômicas, a internacionalização do capital, a concentração das atividades, as disfunções do Banco Central, as elevadas taxas de juros e a vinculação da poupança financeira ao déficit públi$\mathrm{CO}^{7}-$, surgia a ideia de que as normas da futura Constituição tinham, acima de tudo, uma função corretiva: visariam, segundo o Relator Fernando Gasparian, repor "o caráter social das atividades financeiras e a retomada, pelo Congresso

6 Vide a série de publicações Constituição do Brasil e Constituições Estrangeiras, Brasília, Senado Federal, 1987. As disposições constitucionais, em grande maioria, referem-se à emissão de moeda e à organização e funções do Banco Central do que ao Sistema Financeiro no seu conceito mais amplo. Assim, tratam de definir como monopólio governamental a emissão de papel-moeda e delegando tal exercício a uma instituição organizada como banco central, por vezes, arbitrando a receita de senhoriagem. À parte a questão das "emissões de cunho forçado", outro assunto que também merece atenção nas Constituições Estrangeiras respeita ao estímulo e à proteção para poupança popular (vide índice, p. 1270, 1297/98).

7 Relatório da Subcomissão do Sistema Financeiro, Brasília, Assembleia Nacional Constituinte, maio 1987, p. 3-8. 
Nacional, do poder de legislar sobre a matéria financeira". Nesse contexto, a subcomissão aprovou, entre outras medidas:

- A submissão dos interesses das instituições financeiras aos "da coletividade";

- A abertura do mercado a todos que demonstrem idoneidade;

- A nacionalização dos bancos de depósito;

- A delegação ao Congresso Nacional, através de uma comissão especial mista, da competência para legislar sobre a matéria financeira; limitar e autorizar a emissão de moeda e títulos públicos, bem como empréstimos; aprovar orçamentos públicos; e ainda fiscalizar e sustar atos das autoridades monetária e governamentais em geral;

- O disciplinamento das atividades do Banco Central, inclusive dispondo sobre nomeação e mandato de seus dirigentes, e vedando que este financie o governo e o setor produtivo.

Por outro lado, vale destacar que, entre algumas propostas apresentadas pelo constituinte Fernando Gasparian e rejeitadas pelo Plenário da subcomissão, constavam o tabelamento da taxa de juros real (inicialmente, "em 20\% ao ano, decrescendo $2 \%$ a cada semestre, até alcançar o limite de $12 \% "$ ) e a inclusão do volume de moeda emitido na receita do orçamento fiscal da União.

Verificando o andamento do processo constituinte, posterior à fase inicial, e a redação final da Constituição de 1988, constata-se que, no mérito, diversas normas aprovadas pela subcomissão persistiram, na essência, até o final dos trabalhos.

Assim, desde a primeira votação da Assembleia Constituinte, foram decididos e não mais alterados as seguintes disposições sobre a matéria aqui examinada: o fim da exigência da carta-patente para a abertura de instituições financeiras; o referendo pelo congresso às indicações do Presidente da República para direção do Banco Central; a vedação para que o Banco Central financiasse o Tesouro e as instituições não bancárias; e a não responsabilidade da União sobre depósitos e aplicações em instituições financeiras.

\section{COMISSÃO DE FINANÇAS}

A segunda etapa do processo constituinte correspondeu aos trabalhos no âmbito da Comissão do Sistema Tributário, Orçamento e Finanças, que foi presidida pelo constituinte Francisco Dornelles, sendo Relator o constituinte José Serra.

A matéria foi objeto de polêmica, nesta fase, desencadeada a partir das discordâncias manifestadas pelo Relator da Comissão de Finanças, relativamen-

8 Vide Anteprojeto - Redação Final, Subcomissão do Sistema Financeiro, Brasília, Assembleia Constituinte (texto aprovado na reunião de 24.05.1987). 
te ao anteprojeto aprovado pela Subcomissão do Sistema Financeiro. No substitutivo que apresentou em junho de 1987, o constituinte José Serra modificou a forma e o conteúdo do anteprojeto inicial ${ }^{9}$. Com pequenas alterações, as proposições do Relator foram aprovadas pelo Plenário da Comissão de Finanças.

Quanto à estrutura do texto, o Relator José Serra reordenou as disposições em diferentes seções. Destaca-se a distinção entre as normas pertinentes ao Sistema Financeiro e às Finanças Públicas ("a fim de facilitar e melhor sistematizar a abordagem das questões fundamentais"). Além disso, nas normas específicas sobre o Sistema Financeiro, foi atenuado o caráter "autoaplicável" das normas aprovadas pela subcomissão; grande parte das matérias foi submetida ou remetida para o âmbito da legislação infraconstitucional, alegando-se ser uma "importante inovação" que as regras pertinentes à organização e ao funcionamento do Sistema Financeiro constassem da "Lei do Sistema Financeiro Nacional".

No bloco de normas pertinentes ao Sistema Financeiro, vale destacar que o Relator da Comissão de Finanças manifestou particular preocupação com as normas que impactariam a gestão financeira governamental. Em paralelo à Lei do Sistema Financeiro e atribuindo igual importância, ressalta-se, nesta fase constituinte, um Código de Finanças Públicas, para reestruturação do "Sistema Financeiro Público". Entretanto, as normas mais relevantes foram as que refletiam diretamente sobre as finanças e que versavam sobre o Banco Central:

Os princípios de maior transparência, abrangência, participação legislativa, controle e fiscalização das despesas da União têm seu complemento fundamental na clara separação de funções entre o Banco Central do Brasil e o Tesouro Nacional. Transfere-se do Bacen ao Tesouro as atividades que a este são afetas (emissão de títulos de dívida pública e administração de recursos de fomento); de recursos de fomento; que o referido Banco financie direta ou indiretamente o Tesouro e reafirma-se suas funções de autoridade monetária (poder exclusivo de regular a oferta de moeda e a taxa de juros) e guardião das reservas do país. Por último, atribui-se mandato a sua diretoria, cuja nomeação e destituição pelo Presidente da República deverão ser aprovadas pelo Senado Federal.

Outro aspecto fundamental que envolve a utilização dos recursos públicos refere-se à garantia de que as disponibilidades de caixa da União sejam depositadas no Banco Central do Brasil, permitindo:

a) maior controle dos fluxos de recursos;

b) alocação mais racional dos recursos, segundo os propósitos governamentais;

9 Vide Substitutivo do Relator, Comissão do Sistema Tributário, Orçamento e Finanças, Brasília, Assembleia Nacional Constituinte, jun. 1987. Os motivos foram expostos nas páginas 3-5 e uma comparação crítica e pontual com o antreprojeto da subcomissão constou de quadro nas páginas 24-30. 


\section{C) diminuição do custo da dívida interna. ${ }^{10}$}

Vale destacar que no âmbito da Comissão de Finanças foi aprovada norma sugerida pelo Relator, ditando uma regra básica para o relacionamento entre Banco Central e Tesouro e que persistiu até a redação final: a vedação para que aquele financiasse o Tesouro (como qualquer instituição não-financeira) e a permissão para que comprasse e vendesse títulos emitidos pelo Tesouro, "no mercado", como o objetivo de regular a oferta de moeda ou a taxa de juros ${ }^{11}$. A disposição referida surgiu como alternativa a uma proposição da subcomissão que não permitia ao Banco Central, em qualquer hipótese, adquirir títulos do Tesouro (devendo, para efeito de política monetária, emitir títulos próprios). Justificava o Relator da Comissão de Finanças:

[...] imagine-se a ocorrência de calamidade pública de largas proporções, em combinação com uma situação apertada de liquidez na economia. O Governo Federal ver-se-ia obrigado a colocar uma grande quantidade de papéis no mercado, para captar os recursos necessários ao atendimento da calamidade. Como o Banco Central não poderia adquirir esses papéis, o resultado seria considerável elevação de todas as taxas de juros, o que redundaria em prejuízos para o Tesouro Nacional, Estados e Municípios, sem falar no restante da sociedade, duplamente penalizada. Além disso, não podendo adquirir títulos do Tesouro, o Banco Central, para injetar liquidez na economia, teria que adquirir exclusivamente papéis privados. Ou seja, estaria dando mais competitividade a esses papéis privados, assumindo risco maior do que se estivesse adquirindo títulos do Tesouro Nacional e prejudicando a colocação dos títulos federais, que teriam menores vantagens em relação aos papéis privados. ${ }^{12}$

As normas aprovadas pela subcomissão, e mais criticadas pelo Relator José Serra, foram a nacionalização dos bancos e a forma de apreciação da matéria pelo Congresso Nacional, a saber:

- Sobre a nacionalização dos bancos:

[...] Em termos regulamentares é vedada a participação estrangeira em bancos comerciais, e limitada a até $50 \%$ do capital total e até um terço do capital votante, a participação estrangeira nos bancos de investimento, financeiras, corretoras, distribuidoras... Ademais, já é uma realidade a participação de instituições financeiras brasileiras nos mercados internacionais, principalmente o Banco do Brasil... alterando a norma hoje vigente, levará algumas nações a adotarem medidas de retaliação, com o possível fechamento de agências de bancos brasileiros no exterior... a ideia de que esta medida não acarretaria retaliações porquanto as agências brasileiras no exterior captam, preponderantemente, no mercado interbancário, e não diretamente junto ao público ... trata-se de grave erro. ${ }^{13}$

10 Substitutivo do Relator, Comissão, op. cit., p. 4.

11 É curioso registrar que a expressão "no mercado", sugerida pelo relator José Serra (art. $64, \S 2^{\circ}$ ), desapareceu na versão final do anteprojeto da Comissão de Finanças (art. 70, $\S 2^{\circ}$ ).

12 Substitutivo do Relator, op. cit., p. 27

13 Substitutivo, Comissão, op. cit., p. 24-25. 


\section{- Sobre a Comissão Mista Especial do Congresso:}

Ressalte-se, desde logo, a impropriedade de se tratar no texto constitucional matéria atinente ao disciplinamento da forma de como se organizará o Congresso Nacional, para cumprir sua missão constitucional... quanto ao mérito, entendemos que a tarefa de definir e executar políticas - seja em regimes presidencialistas, seja em regimes parlamentaristas - incubem ao governo, no âmbito do Poder Executivo... foram ouvidos representantes dos mais diversos segmentos da sociedade e, se houve uma questão que obteve unanimidade, foi a da absoluta necessidade de serem traçadas regras claras e estáveis para o Sistema Financeiro Nacional. A adoção da medida proposta, a nosso ver, implicaria em se institucionalizar a paralisia do governo e a insegurança no setor privado. ${ }^{14}$

À parte as modificações na estrutura e na própria concepção das normas do Sistema Financeiro, observa-se que as definições da Comissão de Finanças sempre foram pautadas a favor ou contra, a partir das normas aprovadas pela subcomissão.

É verdade que o substitutivo do Relator da comissão representava, em alguns e importantes casos, a rejeição pura e simples de disposição acolhida na fase inicial: como é o caso da supressão da norma que criava uma comissão especial no Congresso Nacional com amplas atribuições sobre matérias monetária e financeira e, em consequência, da que extinguia o Conselho Monetário Nacional imediatamente após a promulgação da Constituição ${ }^{15}$. Mas a maioria das disposições do substitutivo do Relator constituía um desdobramento do que foi aprovado na subcomissão, só que com uma orientação diferente.

Por vezes, na Comissão de Finanças, foi mantido o princípio aprovado pela subcomissão, mas modificada a definição da norma. Por exemplo, no caso da extinção da carta-patente, entendia o Relator que o texto constitucional deveria garantir, de forma ampla e plena, a autorização para o exercício de atividade financeira aos idôneos e capacitados, mas também permitir que isso fosse regulado e eventualmente outras condições estabelecidas na Lei do Sistema Financeiro e pelo Banco Central, sem prejuízo de princípios básicos ${ }^{16}$.

Podem-se citar como outros exemplos de decisões da comissão temática, balizadas pelo aprovado na subcomissão, a inclusão na competência do

14 Substitutivo do Relator, Comissão, op. cit., p. 26.

15 Segundo o relator da comissão, "a ideia de extinguir o Conselho Monetário Nacional é, de fato, bastante aceitável, devido às competências indevidas que a ele têm sido atribuídas, em prejuízo da ação do Congresso Nacional. A rigor, entretanto, a extinção ou não do CMN somente teria sentido no âmbito de uma reforma do Sistema Financeiro Nacional, dando-se nova redação às Leis da Reforma Bancária, do Mercado de Capitais, do Crédito Rural, e legislação complementar" (vide Substitutivo da Comissão, op. cit., p. 30).

16 Conforme o constituinte José Serra, "nos termos em que está redigido o $\S 1^{\circ}$ do art. $2^{\circ}$ do Anteprojeto (Subcomissão), qualquer pessoa poderá opor, ao Banco Central ou à autoridade a quem competir o exame dessa pretensão, o direito de abrir uma instituição bancária, financeira ou cooperativa de crédito, bastando, para tanto, que comprove, no momento da concessão, idoneidade e capacidade técnica, econômica financeira. Dessa forma, tratando-se de direito subjetivo que deflui da própria Constituição, não poderá o próprio Congresso Nacional, em atendimento aos reclamos da sociedade, obstar o exercício desse direito individual, através da legislação ordinária" (Substitutivo, op. cit., p. 24). 
Sistema Financeiro da decisão sobre a autorização para funcionamento de estabelecimentos de seguro, previdência complementar e capitalização; ou a determinação para que as disponibilidades de caixa da União fossem depositadas no Banco Central (e não em instituições financeiras públicas, como pretendia a subcomissão); e a proibição para utilização de recursos na cobertura de aplicações em quaisquer instituições financeiras (e não apenas nas privadas).

A maioria das disposições acolhidas pela Comissão de Finanças representou, na prática, a postergação de decisões para o processo legislativo infraconstitucional. É verdade que há uma característica inovadora na definição da Lei do Sistema Financeiro ${ }^{17}$ e que a regulação de matéria dessa natureza, quisessem ou não os constituintes, depende fundamentalmente de legislação complementar e ordinária.

Porém, mais do que isso, parece que se recorreu ao expediente de remeter decisões para o âmbito da legislação infraconstitucional como forma de contornar os conflitos de posições manifestas nesta primeira fase da Constituinte (evidenciados pelas divergências significativas de opiniões dos Relatores da Subcomissão do Sistema Financeiro e da Comissão de Finanças). Nessa interpretação, as discussões travadas durante a Constituinte fatalmente serão retomadas no processo legislativo complementar. As decisões sobre muitas questões relevantes e com opiniões bastante divergentes ficaram para a competência do Congresso Nacional e, através do poder de veto, do Presidente da República.

Exemplo eloquente é o da participação do capital estrangeiro nas instituições financeiras que funcionam no país. O mercado nacional nem foi mais aberto, nem mais fechado. Deixou-se para a lei complementar a tarefa de decidir as "condições" da participação estrangeira. Apesar de a Constituição prever que, para tanto, a lei considere "os interesses nacionais, os acordos internacionais e os critérios de reciprocidade", essas condições são bastante genéricas e elementares, remetendo para o legislador complementar a tomada das decisões.

É possível mencionar ainda como casos de decisões remetidas para o processo legislativo infraconstitucional: as atribuições do Banco Central; os "impedimentos aplicáveis a quem houver exercido cargo" na diretoria do Banco Central; a formação de fundo para proteger a poupança popular; a contratação de dívidas e a concessão de garantias; a realização de operações de câmbio pela Administração Pública; a fiscalização financeira; e o depósito de recursos públicos em bancos oficiais.

Por vezes, justificava-se que "simples vedações" ou "definições sumárias" não atenderiam - ou pelo menos não o fariam adequadamente - às solu-

17 Não é demais citar que, na legislação vigente, a regulação do Sistema Financeiro e do mercado de capitais está concentrada em duas amplas leis federais (respectivamente, a Lei $n^{\circ} 4.595$, de 1964, e a Lei $n^{\circ} 4.728$, de 1965), que, na prática, já representam uma espécie de código setorial. É verdade que constituem leis ordinárias e não complementares (como foi estabelecido no texto final da Constituinte). 
ções necessárias para os "complexos problemas" envolvidos ${ }^{18}$; ou, então, que a legislação complementar viria a preservar e consolidar as "conquistas" com a reforma do texto constitucional então proposta.

Por último, vale registrar alguns pontos em que o anteprojeto aprovado pela comissão não seguiu o substitutivo proposto pelo Relator constituinte José Serra.

Uma alteração ocorreu no que respeita à direção do Banco Central. O Relator da Comissão de Finanças discordava da proposta da subcomissão, no sentido de que o Congresso aprovasse as indicações feitas pelo Presidente da República e deliberasse sobre as exonerações. Para o constituinte José Serra, o referendum deveria ser dado pelo Senado ("à semelhança do que acontece no caso dos Ministros do Supremo Tribunal Federal e dos chefes de missões diplomáticas"); além disso, entendia que os parlamentares não deveriam ter iniciativa de propor a exoneração dos indicados sob risco de introduzir um elemento permanente de instabilidade no mercado financeiro ${ }^{19}$. Contrariamente a essas opiniões, o anteprojeto aprovado pelo Plenário da comissão (art. 67, parágrafo único) manteve a proposta original da subcomissão.

Nas votações sobre o Sistema Financeiro no Plenário da Comissão de Finanças, o Relator foi derrotado três vezes; aliás, as normas então aprovadas foram mantidas até a fase final dos trabalhos da Constituinte. De um lado, foi prevista a equiparação das cooperativas de crédito às instituições bancárias. De outro lado, atendendo interesses dos parlamentares eleitos nas regiões menos desenvolvidas (majoritárias na comissão) e consoantes com outras mudanças promovidas nas matérias orçamentárias (caso dos critérios para regionalização dos orçamentos e dos planos), foi determinado que os recursos públicos federais para programas regionais fossem depositados e aplicados por instituições regionais de crédito, bem como foi vedada a transferência de "poupança" de regiões mais pobres para as mais ricas ${ }^{20}$.

18 Por exemplo, no caso das atribuições do Banco Central, o relator justificava: "[...] a citação extensiva das funções do Banco Central, adicionada... (à expressão) 'compete, sem prejuízo de outras atribuições que Ihe forem cometidas em lei', é inócua, porquanto faz referência a uma série de assuntos não definidos na própria Constituição (por exemplo, o que é 'programação monetária', 'serviço do meio circulante', etc.), e poderá, no futuro, trazer rigidez desnecessária na regulamentação do funcionamento do Banco Central. O substitutivo procura evitar este problema citando apenas a principal função do Banco Central, que é emitir moeda" (Substitutivo do Relator, op. cit., p. 26-27).

19 Conforme o Substitutivo, op. cit., p. 27: "Suprimiu-se a possibilidade de o Congresso Nacional, sem um quórum qualificado para proposição, tomar a iniciativa do processo de destituição da diretoria do Banco Central. Nesse caso, mesmo se um único parlamentar propusesse o ato mencionado, haveria séria instabilidade no mercado financeiro, pela quebra de autoridade dos dirigentes máximos do órgão fiscalizador e, principalmente, seria ferida, na própria essência, a autonomia que se pretende assegurar ao Banco Central do Brasil, em contradição com a própria proposta da subcomissão".

20 A posição contrária do constituinte José Serra era a seguinte: "Não discordei do espírito ou da intenção que norteou a iniciativa dos seus autores. Meu voto contrário baseou-se na convicção - que mantenho - de que, na redação apresentada, aquelas disposições são impróprias a um texto constitucional, quando não inexequíveis e desvirtuáveis em relação aos próprios objetivos desejados pelos seus autores, especialmente a disposição do Artigo 81 (sobre transferência de poupança entre regiões)" (vide Anteprojeto e Relatório Final, Comissão do Sistema Tributário, Orçamentos e Finanças, Brasília, Assembleia Constituinte, p. 7). 


\section{COMISSÃO DE SISTEMATIZAÇÃO}

Nas seções anteriores foi bastante enfatizado o histórico dos trabalhos desenvolvidos no âmbito da Subcomissão do Sistema Financeiro e da Comissão de Finanças, porque nessas fases debateram-se praticamente todas as propostas que surgiram sobre o tema na Assembleia Constituinte. Inclusive, data daí os debates sobre o chamado "crime da usura" e, o mais importante, na fase da comissão foi decidida grande parte das normas incluídas no texto final da Carta de 1988 (ainda que a redação tenha sofrido pequenas alterações posteriormente).

A fase da Comissão de Sistematização foi iniciada com uma consolidação dos textos das comissões setoriais (chamado Projeto "A"), quando, a partir da proposta do Relator constituinte Bernardo Cabral, se definiu a ordenação final das normas sobre o Sistema Financeiro no texto constitucional. Dividindo em dois blocos as disposições aprovadas pela Comissão de Finanças, o Relator da Sistematização juntou às normas pertinentes aos orçamentos públicos aquelas que faziam referência a atividades e instituições governamentais (como, por exemplo, as relações entre Tesouro e Banco Central), transformando essas disposições em um capítulo (Das Finanças Públicas), o segundo do título dedicado à tributação e ao orçamento (Título VI). Por outro lado, as normas que respeitavam ao que se pode dizer Sistema Financeiro foram transformadas em um capítulo do título dedicado à ordem econômica.

Note-se que como a matéria em apreço não tinha, diretamente, maior interface com matérias analisadas pelas outras seis comissões temáticas da Constituinte (ao contrário, do que ocorreu com a tributação e, principalmente, com os orçamentos, por exemplo), a compatibilização dos anteprojetos setoriais não implicou em qualquer alteração de conteúdo do que fora aprovado na Comissão de Finanças. Exceções a essa regra respeitem à discriminação das competências do Congresso e de suas Casas (por exemplo, sobre o controle do endividamento público).

Para se chegar ao projeto final da Comissão de Sistematização ${ }^{21}$, aprovado em novembro de 1987, foram apresentadas emendas ao texto consolidado que, apreciadas pelo Relator constituinte Bernardo Cabral, resultaram na elaboração do Substitutivo do Relator, que, mais uma vez, recebeu emendas, e ambos, finalmente, foram votados pelo Plenário da comissão.

As votações ocorridas durante a fase da Comissão de Sistematização e que tiveram maior implicação sobre a matéria financeira foram as seguintes:

a) Sobre as leis reguladoras dos Sistemas Financeiros público e privado: Ao contrário do que foi aprovado pela comissão temática, exigiu-se que a lei fosse complementar, e não ordinária, e rejeitou-

21 Comissão de Sistematização, Projeto de Constituição (A), Brasília, Assembleia Nacional Constituinte, nov. 1987. 
-se a figura do "Código de Finanças Públicas", bem como a denominação "Lei do Sistema Financeiro Nacional";

b) Sobre a direção do Banco Central: Suprimiu-se a definição no texto constitucional do período de mandato dos diretores (quatro anos), bem como o referendum parlamentar para exoneração dos mes$\operatorname{mos}^{22}$. Essas decisões, mais uma vez, foram remetidas para a legislação complementar. O Relator da Sistematização, por sua vez, também incorporou, desde o primeiro substitutivo, a transferência da responsabilidade do Congresso para o Senado pela aprovação da indicação e da exoneração dos diretores do Banco Central. A deliberação sobre a demissão pelos senadores foi rejeitada na última rodada de votação;

c) Sobre as atribuições do Banco Central: Os financiamentos e subsídios que o Banco Central vinha concedendo ao setor produtivo, através dos chamados fundos e programas, foram objeto de particular deliberação da Comissão de Sistematização. Não houve maior questionamento sobre a proibição no corpo permanente da vedação para que o Banco Central financiasse instituições não financeiras. Porém, foi rejeitada disposição transitória que previa a transferência para o Tesouro da administração dos fundos e programas, então mantidos pelo Banco Central, que financiavam e subsidiavam o setor produtivo, sob o argumento de que tal norma causaria danos às regiões menos desenvolvidas e ao setor primário da economia, beneficiados pela maior agilidade e bom senso "redistributivo" das autoridades monetárias ${ }^{23}$; e

22 O Referendum para exoneração de diretores foi objeto da 297a Votação da Comissão de Sistematização (ve Diário Assembleia Nacional Constituinte, Suplemento “C”, jan. 1988, p. 1686-1688), sendo que em plenário pronunciou-se contra a participação do Congresso naquele processo o constituinte José Jorge: "[...] já sendo o Presidente do Banco Central aprovado pelo Legislativo, não sendo o Banco Central um órgão do Legislativo, mas do Executivo, não há porque deliberarmos sobre a sua exoneração, mas somente aprovar o novo nome que vier a ser indicado. Por outro lado, ... em determinado momento poderia o Presidente da República exonerar o Presidente do Banco Central e o Legislativo não aceitar essa exoneração. Estar-se-ia criado um problema que não interessa a ninguém...".

23 Vale destacar alguns trechos dos pronunciamentos favoráveis à manutenção das operações no Banco Central na 526 ${ }^{a}$ Votação da Comissão de Sistematização (ver Diário Assembleia Nacional Constituinte, Suplemento "C", jan. 1988, p. 2366-2370).

Segundo o constituinte Oswaldo Lima Filho: "[...] esta medida é profundamente nociva aos interesses daquela região (Nordeste). Desde 1985 o Banco Central tem conseguido elevar as aplicações para os créditos rural e industrial na Região Nordeste de forma altamente significativa... o Tesouro Nacional não tem um funcionário qualificado para fiscalizar o crédito rural ou industrial, não tem atribuições legais, não tem competência, não tem capacidade para aplicar penalidades, mas isto foi feito para que todo o crédito ficasse nas mãos dos seus atuais dirigentes..." (p. 2366)

Do constituinte João Agripino: "[...] o Banco Central estará mais controlado por esta Casa do que a Secretaria do Tesouro Nacional... terá seu presidente e os seus diretores nomeados... com o referendum do Senado da República... a preocupação e o tecnicismo... com relação ao Orçamento também não se justificam. Por quê? Está dito no texto constitucional que esta Casa definirá em lei complementar as atribuições do Banco Central. Por conseguinte, se vamos definir o que é a Carteira de Fomento do Banco Central, ele não poderá fugir da definição que the vamos dar aqui" (p. 2367). 
d) Sobre o controle do endividamento público: No substitutivo do Relator Bernardo Cabral, já tinha caído a proposição da Comissão de Finanças de remeter à legislação complementar a definição de regras gerais para controle e restrição do endividamento público. O senado, que, segundo a Comissão de Finanças, deveria apenas aprovar operações de crédito externo e definir "limites globais" para a dívida estadual ou municipal, incorporou uma série novas atribuições nessa fase, inclusive de limitar os débitos da União e de suas empresas, bem como dispor sobre a dívida mobiliária federal. ${ }^{24}$

\section{PLENÁRIO}

A última e mais importante fase dos trabalhos da Assembleia Constituinte correspondeu à votação, em dois turnos, no Plenário formado por todos os constituintes.

O primeiro turno foi iniciado com a apresentação de emendas alterando o mérito do projeto aprovado pela Comissão de Sistematização. Mas o projeto de sistematização, na condução das votações, perdeu a precedência para as emendas e os destaques apresentados por grupo formado pela maioria dos constituintes - o chamado Centrão. Quanto ao capítulo do Sistema Financeiro, refletindo o grau de aprovação das normas definidas desde as primeiras fases da Assembleia, o Centrão não promoveu quaisquer alterações significativas no texto aprovado pela Comissão de Sistematização.

Em Plenário, no entanto, as votações de emendas individuais sobre o Sistema Financeiro provocaram algumas polêmicas e decisões notórias, sendo aprovadas algumas emendas que mudaram expressivamente o conteúdo do texto até então considerado básico: o disciplinamento das cooperativas de crédito; a restrição para atuação de bancos em atividades não financeiras; o tabelamento da taxa de juros real; a anistia creditícia para micro e pequenas empresas e produtores rurais; e a correção monetária dos débitos das instituições liquidadas ou falidas.

A exigência de que a Lei Complementar do Sistema Financeiro dispusesse também sobre o funcionamento das cooperativas de crédito foi aprovada como fruto de um acordo de lideranças, sem maiores debates em Plenário ${ }^{25}$.

24 Segundo o Substitutivo do Relator da Comissão de Finanças (op. cit.), o Senado deveria ter competência para regular a dívida apenas dos governos subnacionais, na forma definida pela lei complementar, para viabilizar maior autonomia federativa: "Evolução mais significativa apresenta-se na parte concernente às operações de crédito externo e interno... Tais operações também passariam a prescindir do exame caso a caso do Senado Federal. O exame concreto de cada operação e o controle da aplicação dos recursos daí oriundos de endividamento ficariam a cargo dos próprios Legislativos e dos Tribunais ou Conselhos de Contas, respectivamente. Suprime-se o exame caso a caso também para as operações federais. Apenas por exemplo, pode-se prever que... a Petrobrás para fazer uma operação de crédito de um dia no Oriente Médio, por ínfima que fosse, necessitaria da autorização do Congresso. Isto, evidentemente paralisaria sua ação no exterior, assim como a do Banco do Brasil, da Cia. Vale do Rio Doce e etc." (p. 22-26).

25 Vide Diário da Assembleia Constituinte, 12.05.1988, p. 10359-10362. 
A limitação das atividades das instituições financeiras bancárias foi aprovada a partir de emendas dos constituintes José Carlos Coutinho e Aloísio Vasconcelos ${ }^{26}$. A medida inusitada consistia em vedar o acesso das instituições bancárias aos instrumentos que não fossem próprios do que chamavam "mercado financeiro bancário". Na verdade, a maior preocupação dos proponentes era com uma restrição simples e bastante específica: pretendiam impedir a atuação dos bancos no mercado de seguros. Dos dois pronunciamentos favoráveis à fusão de emendas em plenário, é possível destacar os seguintes trechos:

- Do constituinte José Carlos Coutinho:

[...] a democracia tem de ser também econômica e social. Nossa emenda tira dos banqueiros esse super poder que têm de nos coagir nas suas agências bancárias, quando vamos apanhar um empréstimo, e nos impingir seguro de vida, seguro de automóvel, ações do próprio banco... Peço, pois, a esta Constituinte... que nos dê apoio da democratização do capital, permitindo a participação a nossa sociedade em todos os mercados, em igualdade de condições. ${ }^{27}$

- Do constituinte Aloisio Vasconcelos:

A proposição... é muito simples. É a separação do sistema bancário de seguros. É a decisão para acabar com o chamado supermercado dos bancos, pois o banco vende passagens, seguros e ações, por exemplo. Pretende-se, então, que banco seja banco, e companhia de seguro, com seus corretores, seja de fato companhia de seguro, ou seja, especificar as atribuições das instituições $[. ..] .^{28}$

As emendas foram aprovadas com apenas nove votos acima do quórum mínimo necessário (289 votos sim) ${ }^{29}$. Os pronunciamentos contrários alegaram que representavam a constitucionalização de um "cartório" ou uma "reserva de mercado" para intermediários de seguros, bem como que poderia inviabilizar os serviços financeiros tradicionalmente prestados pelos bancos e não apenas os relativos a seguros ${ }^{30}$.

A norma mais importante e polêmica sobre o sistema financeiro aprovada no primeiro turno do Plenário da Constituinte foi outra e respeitou à fixação de um teto para a cobrança de juro real, até $12 \%$ a.a., e a definição de que a exigência de juro acima desse percentual passaria a constituir crime de usura.

26 Vide Votação no Diário da Assembleia Nacional Constituinte, 12.05.1988, p. 10355-10359.

27 Constituinte José Carlos Coutinho, Diário, op. cit., p. 10355.

28 Constituinte Aloisio Vasconcelos, Diário, op. cit., p. 10356.

29 Duas peculiaridades da votação dignas de nota. Primeiro, um dos autores da sugestão que implicava em limitar a atuação de um segmento empresarial - o constituinte José Carlos Coutinho - pertencia ao Partido Liberal, que pela própria denominação expressava sua orientação político-ideológica. Segundo lideranças de matizes ideológicas as mais distintas encaminhavam favoravelmente: desde o PL e o PTB até o PT e o PC do B (o voto ficou em aberto no PDT e no PMDB; por outro lado, foi contrário das lideranças do PDS e do PFL).

30 Nesse caso manifestou o constituinte César Maia: "[...] uma coisa é a intenção dos autores da emenda, outra coisa é o que esta escrito no texto...É um absurdo, porque proíbe os bancos, por exemplo, de pagarem os aposentados ou pensionistas, de receberem contas de luz, de gás, de telefone e de receberem o pagamento do Imposto de Renda. Por que? Porque eles apenas podem receber aplicações e fazer aplicações..." (Diário, op. cit., p. 10356). 
Ela resultou de emenda proposta pelo constituinte Fernando Gasparian, que já tinha tentado, sem sucesso, aprovar essa sugestão nas fases anteriores, desde que foi Relator da Subcomissão do Sistema ${ }^{31}$.

A norma foi justificada tanto a pretexto de desmontar a "ciranda financeira" que dificultava o desenvolvimento econômico do país, como também pela retomada da ideia de que a intermediação financeira poderia e seria perniciosa para a economia e a sociedade, havendo um conflito entre o capital não financeiro e o financeiro. Chama-se a atenção que, nesse contexto, a ideia não constitui apenas uma bandeira de posições, pode-se dizer, nacionalistas e ligadas à moral cristã; mais do que isso, representou também um conflito aberto e interno ao segmento empresarial brasileiro: os devedores, representados basicamente pelo capital agrário, contra credores, o capital financeiro.

É possível destacar trechos selecionados dos dois encaminhamentos favoráveis ao tabelamento dos juros realizados durante a votação em Plenário:

- Do constituinte Gastone Righi:

[...] a presente emenda talvez seja - e para mim seguramente o é - uma das mais importantes proposituras submetidas à análise desta Assembleia... Na realidade, a emenda restabelece em sua plenitude a Lei de Usura, que ainda vigora entre nós, mas que, pela sucessiva legislação e entendimento pretoriano, acabou cingida aos particulares, isentando as entidades e instituições financeiras da obrigação de obedecerem a ela... Sabemos todos... que o Brasil se debate nessa crise em razão de uma inflação galopante, que avilta os salários e reduz à indigência os trabalhadores, mas que faz a opulência daqueles que vivem do mercado financeiro. É a ciranda financeira implantada, é o autêntico festival de Baltazar, festim onde o dinheiro do povo e o dinheiro público são consumidos em juros extorsivos sobre os particulares e as entidades públicas... A emenda, portanto, quando procura restabelecer dentre nós pelo menos os princípios éticos, para que haja parâmetros na cobrança de juros não exorbitantes, é resultado de tarefa constitu-

31 Vide votação na Sessão de 11.05.1988, publicada no Diário ANC, 12.05.1988, p. 10362-10367.

Aliás, uma observação atenta dos Anais da Assembleia Constituinte revela uma pequena, porém, importante alteração entre o texto submetido à votação e aprovado e o que constou do relatório final dos trabalhos do primeiro turno em plenário. A votação resultou do Requerimento de Destaque $n^{\circ} 1.298$; nas palavras do Presidente da Mesa, constituinte Ulysses Guimarães: "É a seguinte a matéria destacada: Emenda n 1.498. Do Sr. Fernando Gasparian. Inclua-se o seguinte inciso no art. 228, referente ao Sistema Financeiro Nacional, [...] VII - as taxas de juros reais, [...] O nobre constituinte Fernando Gasparian quer incluir no art. 225 um inciso aditivo..." [grifo nosso] (p. 10362). Sobre o que foi votado, vale citar também publicação da SecretariaGeral da Mesa ("Mapas demonstrativos da Matéria Aprovada em Primeiro Turno pelo Plenário - Sessões de 27.01.1988 a 30.06.1988", jul. 1988), que, na sessão de 11.05.1988, assim identifica a votação do destaque mencionado: "Art. 225 da Emenda n ${ }^{\circ}$ 2043-7" (a emenda citada é a substitutiva do grupo Centrão). Os pronunciamentos seguintes, em plenário, em nenhum momento, versaram sobre qualquer alteração nessa proposta.

No entanto, feita a "redação do vencido" pelo Relator-Geral, que constitui o denominado "Projeto de Constituição (B)", o texto aprovado pelo plenário foi apresentado como um novo parágrafo (o $3^{\circ}$ ) e não é demais registrar que, posteriormente à promulgação da Constituição, desenvolveram-se intensas discussões, culminando com disputas judiciais, sobre o caráter "autoaplicativo" ou não da disposição constitucional em questão; inclusive, com uma das partes, defendendo que, como um parágrafo do artigo, o tabelamento da taxa de juros real não dependeria da aprovação da lei complementar sobre o sistema financeiro para entrar em vigor. 
cional... É preciso restabelecer um mínimo de vergonha nacional - vergonha aqui que se consubstancia num limite máximo a sanha da cobrança de juros. Basta!... Estão restabelecidos entre nós os primados do valor do trabalho acima da exploração do empréstimo capitalista [...]..$^{32}$

\section{- Do constituinte Mário Assad:}

[...] somos representantes do povo e que aqui estamos para atender aos anseios da agricultura, da mini, média e pequena indústrias, do trabalhador, do proprietário e, acima de tudo, de toda a Nação brasileira... este país está falido por causa exclusivamente desses juros escorchantes que estão levando agricultores de minha região... até ao suicídio... povo que sofre e vive desgraçadamente, trabalhando para $1 \%$ dos banqueiros viverem poderosamente nesta Nação... Não é possível que se deixe falir as empresas e a agricultura deste país... o banco, que também tem função social, deve assumir a parcela que lhe cabe na área social deste país... não vamos aceitar a alegação de que essa matéria não é constitucional. Rui Barbosa sempre pregou que constitucional é tudo aquilo que parte da alma do povo, bem como o que atende aos anseios populares [...]. ${ }^{33}$

Os pronunciamentos contrários durante a votação (votos encaminhados pelos constituintes José Serra e César Maia) insistiram nos aspectos de que a matéria não seria própria da Constituição, influenciada por fatores conjunturais e, sobretudo, pela orientação da política econômica; não haveria como ser operacionalizado o limite no caso de empréstimos prefixados e isso inviabilizaria a medida na prática; e poderia levar a outras distorções no sistema como fuga de capitais $^{34}$.

A decisão não foi marcada por posições políticas ou ideológicas claras. A começar, votação, encaminharam a favor os líderes dos partidos PC do B, PTB, PDC, PSB, PCB, PDT e PT; o PMDB deixou a questão em aberto, mas seu representante (constituinte Severo Gomes) declarou que votaria favoravelmente;

32 Constituinte Gastone Righi, Diário, op. cit., p. 10362/3.

33 Constituinte Mário Assad, Diário, op. cit., p. 10363.

34 Segundo o constituinte José Serra: "O problema é a pertinência, a propriedade e a eficácia de estabelecer-se tabelamento de juros numa Carta Constitucional; além do mais, baseado num conceito que é extremamente vago, quando se vai medir em termos jurídicos o que é taxa de juros real... depende da estrutura e do funcionamento do Sistema Financeiro que organizaremos numa lei complementar... depende da inflação, depende de expectativas, do déficit público, da política monetária, da inflação externa... Para combatê-la devemos ter uma política econômico-financeira monetária adequada, não uma fixação simplesmente..." (Diário, op. cit., p. 10363).

Já o constituinte César Maia destacou as distorções sobre as operações financeiras prefixadas: "Só existe no mundo um país que opera com taxas de juros pós-fixadas: o Brasil. 0 que acontece quando se impede na Constituição o funcionamento com taxas nominais, ou seja, prefixadas? Sempre que a inflação prevista for menor do que a real, haverá devolução de dinheiro por parte do banqueiro. Sempre que a inflação for maior do que a real, haverá devolução de dinheiro por parte do tomador de empréstimos, o que é um absurdo. Mais ainda: o tabelamento é em nível máximo; todo sistema oligopolizado... tem de fazer os preços ficarem acima dessa tabela... o governo fica limitado na sua política monetária e fiscal em relação ao Sistema Financeiro, privilegiando exatamente o que se quer combater. Pergunto: onde se pensa que está o IOF? Ele faz parte dos juros pagos pelo tomador... A economia brasileira funciona junto à economia internacional. Flutuações ocasionais de juros nominais no exterior vão produzir... evasão de recursos para o exterior" (Diário, op. cit., p. 10364). 
apenas PDS e PFL pediram voto não. O parecer do Relator foi anunciado pelo Presidente da Mesa como sendo contrário à proposição, mas, na votação, o Relator geral, constituinte Bernardo Cabral, optou pela abstenção ${ }^{35}$.

Destaca-se também que a observação da relação individual de votação revela posições favoráveis de constituintes de orientações ideológicas e partidárias as mais contraditórias ${ }^{36}$. O crime de usura foi aprovado por 314 votos, sendo 112 os votos negativos.

Sobre a aprovação do teto para o juro real, é curioso registrar as semeIhanças entre a justificação da emenda e os encaminhamentos favoráveis em Plenário da emenda do constituinte Gasparian com as propostas de restrição da atuação dos bancos.

Os dois debates, sobre o crime de usura e sobre a restrição da atuação dos bancos, foram polarizados pelo choque de interesses entre o Sistema Financeiro e os seus devedores, marcadamente os agricultores. Característica básica dos discursos em Plenário nas duas ocasiões foi a aversão à atividade bancária (ao menos nos moldes em que vem se dando no país) e, em consequência, a tentativa de impor limites ou mesmo penalização aos intermediários financeiros. Isso ficou evidenciado nos mapas individuais de votação que revelam uma elevada correlação de votos favoráveis as duas emendas citadas: 240 constituintes votaram "sim" nas duas vezes, ou seja, $83 \%$ dos constituintes que aprovaram a restrição para atuação dos bancos em seguida também aprovaram o crime de usura e $76 \%$ dos constituintes que apoiaram o teto para o juro real tinham aprovado antes a limitação às atividades bancárias.

Outra mudança sobre o Sistema Financeiro de grande destaque durante os trabalhos do primeiro turno do Plenário ocorreu no âmbito das disposições transitórias, envolvendo a aprovação, em duas votações, da concessão de anistia da correção monetária na liquidação de empréstimos contratados, durante o período do Plano Cruzado, por micro e pequeno empresários/empresas, bem como por mini, pequeno e médio produtores rurais.

35 Vale citar também que, no encaminhamento da matéria, foi solicitado ao Relator Bernardo Cabral responder duas perguntas sobre o efeito da emenda proposta e, dentre outras coisas afirmou: "[...] Havia dado um parecer contrário, por escrito, e não me manifestei porque a argumentação trazida pelo eminente constituinte Mário Assad comoveu muito a Casa... Mas o constituinte Fernando Gasparian quer declarar que são taxas de juros reais. V. Exas. acabaram fazendo a pergunta aos mais aficcionados. Se o eminente constituinte Delfim Netto esta achando estranho o modo como se calculará isso, muito mais eu, que não fui Ministro da Fazenda. Agora, Sr. Presidente, a questão é realmente contraditória e polêmica, Acho que V. Exa. deveria indagar - e aí seria o mens legis - o que pretende o constituinte Fernando Gasparian" (Diário, op. cit., p. 10364).

36 A título de ilustração, vale citar, por exemplo, que aprovaram a emenda do constituinte Gasparian desde os constituintes Brandão Monteiro, Cristina Tavares, Euclides Scalco, Jamil Haddad, Roberto Freire, Pimenta da Veiga, Plínio Arruda Sampaio, Severo Gomes e Luis Inácio Lula da Silva, até Affonso Camargo, Carlos Chiarelli, Fernando Bezerra Coelho, Gastone Righi, Geraldo Bulhões, Gerson Camata, Humberto Souto, Itamar Franco, José Carlos Vasconcelos, José Ignácio Ferreira, José Maria Eymael, Lavoisier Maia, Luis Roberto Ponte, Odacir Soares, Roberto Cardoso Alves e Renan Calheiros. 
O beneficio creditício acabou limitado aos "pequenos" financiamentos e empreendimentos. Os constituintes manifestaram preocupação em não acarretar ônus ao governo. Mas, ao mesmo tempo, foi determinado que esse ônus recaísse sobre "a fonte de recursos originária" (que era o próprio Tesouro Nacional, pois grande parte das operações era feita por meio dos fundos e programas do chamado orçamento monetário).

A aprovação da anistia creditícia ${ }^{37}$ foi obtida, mais uma vez, com argumentos semelhantes aos desenvolvidos na defesa do tabelamento da taxa de juros e da restrição à atuação dos bancos, como indicam estes trechos selecionados entre os dois pronunciamentos favoráveis feitos em Plenário:

- Do constituinte Vicente Bogo:

[...] em primeiro lugar, a fusão aqui examinada não representa nenhuma costura, nenhuma articulação do latifúndio, da UDR, dos setores conservadores ou de oportunidades que querem aproveitar o momento para obter privilégios... Os produtores rurais que também contraíram débitos para produzir no país durante o chamado período Bresser estão hoje impossibilitados de pagar seus débitos, na eminência de serem jogados nas favelas e de perderem seu instrumento de trabalho e o sustento de suas famílias [...]. ${ }^{38}$

- Do constituinte Humberto Souto:

[...] apresentamos esta emenda porque entendemos que este país saberá separar o homem que produz e trabalha daquele que especula no mercado financeiro... Ninguém neste país parece se preocupar com o homem que planta o feijão, o arroz, o milho. Mas há uma preocupação por parte daqueles que defendem os banqueiros e o governo... No interior mais longínguo [sic] deste país, os bancos, na sua voracidade do lucro, eliminam, assassinam, matam milhares e milhões de brasileiros, através dos juros cobrados às microempresas e à produção rural. Isto que é importante. Esta é uma emenda que não tem partidos, não tem fronteiras, não tem ideologias, e está acima dos interesses dos líderes [...]. ${ }^{39}$

Sobre a coincidência de posições entre os constituintes que aprovaram a restrição à atuação dos bancos e o crime de usura, e os que apoiaram a anistia creditícia, vale acrescentar que uma análise comparativa dos mapas de votação indica que 161 constituintes votaram a favor nas três vezes - isto é, $51 \%$ dos que aprovaram a limitação do juro real e $56 \%$ dos que aprovaram as outras duas emendas.

37 A emenda básica foi aprovada por 286 votos contra 163, tendo recebido apoio das lideranças do PDT, PDC, PC do B e PSB, ficando a questão em aberto no PMDB, PTB e PDS, e tendo posição contrária do PT e do PDS (vide Diário, op. cit., 30/06088, p. 11766-11774). A emenda que restringiu a distribuição dos subsídios creditícios foi aprovada por 297 contra 115 votos, sendo apoiada pelas lideranças de todos os partidos supracitados (vide Diário, op. cit., 30.06.1988, p. 11778-11783).

38 Vide Diário, op. cit., 30.06.1988, p. 11767.

39 Vide Diário, op. cit., 30.06.1988, p. 11768. 
As votações das disposições transitórias, no primeiro turno do Plenário, envolveram ainda uma norma referente ao Sistema Financeiro que, em um dos raros momentos da Assembleia Constituinte, foi aprovada com 387 votos "sim", contra apenas 1 (um) voto negativo ${ }^{40}$ e 9 abstenções: a correção monetária dos créditos do Bacen e do antigo $\mathrm{BNH}$ junto às instituições financeiras em processo de intervenção, liquidação ou falência ${ }^{41}$.

Sendo a fase de Plenário a mais importante da Assembleia Constituinte, não é demais mencionar algumas votações que, embora não tenham tido resultado positivo (isto é, não tenham incorporado alterações ao futuro texto constitucional), envolveram as seguintes questões-chave para a estruturação do Sistema Financeiro:

a) Estatização das instituições financeiras ${ }^{42}$;

b) Vedação para funcionamento no país de instituição controlada por capital externo ${ }^{43}$;

40 Do constituinte Homero Santos

41 Vide votação no Diário, op. cit., 30.06.1988, p. 11747-11750, de emenda de autoria do constituinte Oswaldo Lima Filho.

No único encaminhamento feito em plenário, o constituinte José Serra assim defendeu a proposta: "Esta emenda reproduz, de fato, o Decreto-Lei n².015, de fevereiro de 1983, de maneira a evitar a invocação da irretroatividade por parte dos autores dos crimes de colarinho branco, até hoje impunes e, de certa maneira, desfrutando da situação de falência de instituições financeiras. Uma norma constitucional como esta, repondo aquela disposição posteriormente revogada, permitirá evitar essas situações que o país tanto tem lamentado... Em face da alta inflação existente e da circunstância de que a correção monetária das dívidas passadas passou a ser suspensa, mantendo-se, por outro lado, a atualização do ativo, houve rapidamente uma inversão na situação, fazendo aparecer um lucro tão mais elevado quanto maior o período de liquidação extrajudicial..." (p. 11747).

42 Vide votação de emenda do constituinte Luiz Gushiken no Diário da Assembleia Nacional Constituinte, 12.05.1988, p. 10351/10354.

Nos pronunciamentos em plenário, o autor da emenda defendeu:

"[...] o conceito de função social deve ser aplicado ao setor financeiro no Brasil, porque é inadmissível vermos milhares de pequenos e médios empresários - em particular os do campo - sofrendo a amargura da falência, incapacitados de pagar os juros escorchantes cobrados pelos banqueiros... O papel do Estado no setor financeiro é condição para alavancar e para que as empresas do setor produtivo tenham recursos que não sejam alocados para a especulação financeira... há que se manter um controle que vai desde a alta cúpula de um banco até o ponto terminal, no caso o gerente, na aplicação dos recursos públicos."

Encaminhou contra a emenda o constituinte Osmundo Rebouças:

"[...] se o oligopólio existente contribui para aumentar a taxa de juros, muito pior seria o monopólio, que economicamente é um regime ineficiente... Na verdade, a estatização aumentaria e não diminuiria as taxas de juros... o Estado deve regular, controlar a atividade econômica e estabelecer normas, a fim de evitar os abusos do agente financeiro, mas jamais executar diretamente essa atividade..."

Apoiaram a emenda as lideranças do PT, PDT, PCB e PC do B. É curioso que o PTB deixou a questão em aberto, mas seu líder, constituinte Gastone Righi, votou favoravelmente, assim como outros parlamentares considerados liberais (como Arnaldo Faria de Sá, César Maia, Itamar Franco, João Agripino, José Maria Eymael, Paes de Andrade e Renan Calheiros). O resultado foi 136 votos "sim" e 316 "não".

No primeiro turno de plenário ainda foi votada e igualmente rejeitada emenda do constituinte Aluízio Bezerra visando a "federalização" do Sistema Financeiro, ou seja, passando o controle de todas as instituições financeiras para as mãos do Governo Federal (vide Diário, op. cit., 12.05.1988, p. 10372-10375).

43 O constituinte Nelton Friedrich defendeu a "nacionalização" alegando, dentre outros fatores, que os Estados Unidos "[...] desde sua independência praticamente proíbe ou limita os bancos de depósitos de país 
c) Concessão de empréstimos à agricultura e às microempresas com recursos públicos federais, exclusivamente através de bancos oficiais ${ }^{44}$;

d) Limitação da atuação territorial de um banco ao estado onde se localiza sua sede ${ }^{45}$; e

e) Vedação para emissão de títulos ao portador ${ }^{46}$.

Ao final da primeira rodada de votações em Plenário, estavam definidas as normas sobre o Sistema Financeiro da futura Carta. No segundo turno das votações em Plenário, regimentalmente cabiam apenas emendas supressivas; não podia mais ser modificada a redação aprovada no primeiro turno ${ }^{47}$. Nessa fase, houve ainda tentativa, sem sucesso, de se suprimir a restrição para que os bancos atuassem nos mercados de seguros e outros ${ }^{48}$.

Na Comissão da Redação final, encarregada de fazer a última revisão do texto do Projeto de Constituição "D", aprovado em plenário (com atenção especial à ortografia), foi realizada uma mudança no tocante ao Sistema Financeiro. Todas as citações do "Banco Central", que deste modo apareciam no Projeto até então - ou seja, com as letras iniciais em maiúsculo -, foram substituídas pela expressão "banco central", com iniciais em minúsculo, conforme declarado pelos revisados com o propósito de "não transformar aquela autarquia federal em um ente constitucional".

Menciona-se, ainda, que uma disposição constitucional que respeita em parte ao sistema financeiro respeita a destinação obrigatória de $40 \%$ da arrecadação da contribuição ao PIS/Pasep para financiar projetos de investimen-

estrangeiro... Esta é uma prática que existe, em maior ou menor intensidade, na Suécia, na Coréia, na Argélia, na Venezuela... No Brasil, há total liberdade...".

Em oposição, o constituinte Osmundo Rebouças argumentou que "atualmente, nenhum banco estrangeiro pode adquirir ações de bancos brasileiros. Por essa emenda, os bancos estrangeiros poderão adquirir $49 \%$ do capital de todos os bancos brasileiros..." (vide Diário, op. cit., p. 10367/8).

44 Emenda do constituinte Nyder Barbosa, que chegou a obter uma votação favoravelmente expressiva (228 votos), em grande parte, devido ao apoio dado pela liderança do PMDB (vide Diário, op. cit., 12.05.1988, p. 10375-10379).

45 Proposta do constituinte Vivaldo Barbosa, que assim discursou: "O Sistema Financeiro vigente corrói e destró qualquer ideal federativo... No nosso Sistema Financeiro, as poupanças locais e regionais são drenadas para os grandes centros financeiros... As regiões mais empobrecidas, as menos industrializadas são as que não possuem qualquer sistema financeiro próprio e local... A história americana seguiu outro rumo... Na maioria dos Estados, cada estabelecimento bancário só pode operar em uma cidade..." (vide Diário, op. cit., 12.05.1988, p. 10379-10382).

46 Foi votada proposta apresentada pelo constituinte Luiz Salomão, que, em plenário, justificou:

“[...] não é apenas um ponto de vista tributarista que estou defendendo... É também uma questão ética do mercado acionário, que precisa ter transparência para que o controle na sociedade por ações fique visível, seja pela sociedade civil, seja pelo poder público..." (Vide votação no Diário, op. cit., 12.05.1988, p. 10382/10385)

47 No segundo turno, embora regimentalmente não coubesse, foi aditada uma pequena expressão, por acordo de lideranças, à disposição que tratava do funcionamento das instituições bancárias: esclarecendo que os bancos estavam vedados de participar em atividades que não as especificadas no inciso I do art. 197 (na referencia ao texto do projeto aprovado no primeiro turno).

48 Vide Diário da Assembleia Constituinte, 30.08.1990, p. 13719-13727. 
tos por meio do Banco Nacional de Desenvolvimento Econômico e Social - o BNDES. A proposta foi examinada em meio àquelas previstas no âmbito da ordem social, originalmente sendo uma das disposições transitórias vinculadas a tal título, mas, na fase final de Plenário, acabou sendo remanejada para o corpo permanente, renumerado como o art. 239, integrante do título das disposições constitucionais gerais (o que, na prática, significou uma espécie de "constitucionalização" daquele banco estatal de fomento, em direção oposta ao tratamento dispensado ao banco central).

\section{OBSERVAÇÕES FINAIS}

As deliberações da Assembleia Nacional Constituinte sobre o Sistema Financeiro Nacional refletem naturalmente o contexto histórico, econômico, político e social em que o processo foi conduzido. Não faltaram inovações e polêmicas em torno dessa matéria. A começar pela opção de se dedicar um capítulo específico ao tema, que seria próximo ao de tributação e orçamento, pela forma como foram organizados os trabalhos iniciais da Constituinte (fases das subcomissões e comissões), mas acabou inserido como o último do título da ordem econômica.

Desde a primeira fase da subcomissão até a mais importante de todas, o primeiro turno de votações em Plenário, proliferaram propostas que se pode qualificar como populistas, nacionalistas e estatizantes. Algumas sugestões mais radicais, como a nacionalização e a estatização do sistema bancário, não chegaram a ser aprovadas, mas foram defendidas abertamente.

Mas algumas proposições que foram aprovadas não ficam muito atrás nesse requisito, em especial o caso do tabelamento da taxa de juros e da anistia aos produtores rurais que tomaram crédito oficial. E tais deliberações foram tomadas em Plenário e depois que o grupo dito mais conservador, o Centrão, tinha vencido o projeto oriundo da comissão de sistematização, em que predominaria os progressistas, mas que não tinha acolhido aquelas propostas. Ainda que as normas heterodoxas antes citadas não tenham feito parte da emenda do Centrão, os seus líderes comandaram a aprovação, obviamente apoiados por constituintes que direta ou indiretamente possuíam ou sofriam com dívidas bancárias, mas com uma curiosa e peculiar aliança com os parlamentares tidos como mais à esquerda.

Não muito distante desse caráter populista, a questão regional, que foi muito cara aos debates sobre a reforma tributária, também se fez presente nas deliberações sobre o Sistema Financeiro, como na inclusão de uma curiosa norma que proibia a transferência de poupança captada nas regiões menos desenvolvidas para as demais.

Derrotados e minoritários nesses debates e nessas deliberações, os constituintes com maior formação e experiência em economia e finanças quando 
muito conseguiram, como paliativo, que o futuro texto constitucional remetesse a regulamentação da matéria para lei complementar. Esse foi o caso dos incisos do caput do art. 195, que enumerava um amplo e variado elenco de normas a serem reguladas por tal, que não se limitavam apenas à estruturação do sistema e à organização do banco central. O que foi incluído nos parágrafos, muitos constituintes acreditavam que seria autoaplicável, caso notório do tabelamento dos juros, acabou vinculado à vigência da mesma lei geral sobre o sistema, por deliberação do STF.

A deliberação da justiça e a dificuldade de transformar em prática muito do que foi decidido na Constituinte, em especial em torno das normas que se podem qualificar como atípicas entre as que regulam o Sistema Financeiro (para não se dizer, populistas), acabou motivando a apreciação de uma proposta de emenda constitucional que, depois de tramitar por alguns anos, veio a ser promulgada no início de 2003. Curiosamente, a iniciativa desta proposta foi de um Senador, que tinha sido constituinte e relator da matéria na fase da comissão temática, José Serra, e quando promulgada, foi a primeira emenda realizada no governo do Presidente Luis Inácio Lula da Silva, que também tinha sido constituinte - e os dois tinham disputado uma eleição presidencial poucos meses antes. De certa forma, é possível dizer que as divergências e os embates parlamentares, que perduraram durante todo o processo constituinte em torno da matéria financeira, persistiram e só foram resolvidos quinze anos depois.

Do longo e prolixo texto que constituía o art. 192, promulgado em outubro de 1988, com vários incisos e parágrafos, a partir da emenda de 2003, foi sensivelmente reduzido. Sobreviveu a espécie de lipoaspiração apenas um enunciado de caráter pragmático: "[...] estruturado de forma a promover o desenvolvimento equilibrado do País e a servir os interesses da coletividade, em todas as partes que o compõem...". Aliás, é interessante mencionar que tal princípio definido pelos Constituintes de 1987/88 guarda enorme semelhança com os enunciados presentes nas Constituições de Portugal (art. 105) e do Peru $(\text { art. 152) })^{49}$.

De qualquer forma, a emenda de 2003 repetiu e até ampliou uma prática comum ao processo constituinte originário: impasses e embates são remetidos para regulamentação posterior. A nova redação define que o sistema "[...] será regulado por leis complementares..." - não detalha sobre o que elas disporão, apenas exige que tratem da participação do capital estrangeiro. O plural é um detalhe importante, pois mantém o caráter inédito, para não dizer exótico, que cercou a matéria desde a Assembleia Constituinte, pois é o único em meio ao

49 A Constituição portuguesa assim dispõem em seu art. 105: "O sistema financeiro é estruturado por lei, de modo a garantir a formação, a captação e a segurança das poupanças, bem como a aplicação de meios financeiros necessários à expansão das forças produtivas, de acordo com os objetivos definidos no Plano".

Já a Constituição peruana define em seu art. 152 que: "La actividad bancaria y financiera cumple función social de apoyo a la economia del pais en sus diversas regiones y a todos los sectores de actividad y población de acuerdo con los planos de desarollo". 
extenso e longo corpo permanente da Constituição vigente em que se remete a regulação não a uma, mas a mais de uma lei complementar.

\section{REFERÊNCIAS}

AFONSO, José Roberto. Memória da Assembleia Nacional Constituinte de 1987/88: as finanças públicas. Revista do BNDES, Rio de Janeiro: BNDES, n. 11, jun. 1999. Disponível em: http://bit.ly/Zyyffp.

BRASIL. Senado Federal. Constituições do Brasil. Brasília: Subsecretaria de Edições Técnicas, 1986.

Constituições do Brasil e Constituições Estrangeiras. Brasília: Subsecretaria de Edições Técnicas, 1987.

Assembleia Nacional Constituinte. Relatório da Subcomissão do Sistema Financeiro. Brasília, maio 1987. 1987.

Assembleia Nacional Constituinte. Anteprojeto e Redação Final. Brasília, maio

Assembleia Nacional Constituinte. Substitutivo do Relator, Comissão do Sistema Tributário, Orçamentos e Finanças. Brasília, jun. 1987.

Assembleia Nacional Constituinte. Projeto de Constituição (A), Comissão de Sistematização. Brasília, nov. 1987.

Assembleia Nacional Constituinte. Diário da Assembleia Nacional Constituinte (Diário da ANC). Brasília, 12.05.1988, diversos números.

DIAS, Guilherme Gomes; AFONSO, José Roberto; PATURY, Luiz Carlos Romero;

PARENTE, Pedro Püllen. A lei complementar do sistema financeiro nacional: subsídios e sugestões para sua elaboração. Cadernos de Economia, Rio de Janeiro: IPEA - Instituto de Pesquisa Econômica Aplicada, n. 7, abr. 1992.

PATURY, Luis Romero. Lei complementar sobre finanças públicas e sobre sistema financeiro. Cadernos de Economia, Brasília: IPEA, n. 7, abr. 1992.

TORRES, Ricardo Lobo. Curso de direito financeiro e tributário. 3. ed. atual. e ampl. Rio de Janeiro: Renovar, 1996. 